\title{
Candida auris Biofilm on ECMO Cannulas
} \author{
Vilella ${ }^{4}$, Pemán $\mathrm{J}^{5}$ and Ramírez $\mathrm{P}^{1}$ \\ ${ }^{1}$ Department of Critical Care, Hospital UniversitariiPolitècnic la Fe, Valencia, Spain \\ ${ }^{2}$ Microscopy Unit,Hospital UniversitariiPolitècnic la Fe, Valencia, Spain \\ ${ }^{3}$ Department of Cardiac Surgery, Hospital UniversitariiPolitècnic la Fe, Valencia, Spain \\ ${ }^{4}$ Department of Cardiology, Hospital UniversitariiPolitècnic la Fe, Valencia, Spain \\ ${ }^{5}$ Department of Microbiology, Hospital UniversitariiPolitècnic la Fe, Valencia, Spain
}

Gimeno Costa $\mathbf{R}^{* 1}$, Gordón $\mathbf{M}^{1}$, Marín $\mathbf{M P}^{2}$, Pérez $\mathrm{F}^{1}$, Madrid $\mathbf{I}^{1}$, Hevia $\mathrm{L}^{1}$, Talavera $\mathbf{M}^{1}$, Doñate $\mathbf{L}^{3}$, Lopez

Corresponding author: Ricardo Gimeno Costa, Critical Care Department, Hospital UniversitariiPolitècnic la Fe,Avda Fernando Abril

Martorell 106, Valencia, Spain

\section{ARTICLE INFO}

Received: 幽 October 10, 2020

Published: 慧 October 20, 2020

Citation: Gimeno Costa R, Gordón M, Marín MP, Pérez F, Madrid I, et al. Candida auris Biofilm on ECMO Cannulas. Biomed J Sci \& Tech Res 31(2)-2020. BJSTR. MS.ID.005078.

Abbreviations: ECMO: Extracorporeal Membrane Oxygenation; ELSO: Extracorporeal Life Support Organization; HAI: Healthcare-Associated Infections; ICU: Intensive Care Unit; Cryo-SEM: CryoScanning Electron Microscopy

\section{ABSTRACT}

Introduction: Candida auris has become an important multidrug resistant pathogen and there are several publications that show its ability to form biofilm in vitro. The formation of biofilms on biomaterials constitutes a reservoir of microorganisms and hinders the action of antibiotics.

Clinical Case: A 44-year-old man was admitted to the Intensive Care Unit with a diagnosis of cardiogenic shock due to an acute myocardial infarction. Extracorporeal Membrane Oxygenation (ECMO) was required. During the therapy, Candida auris was isolated in microbiological cultures, including blood cultures and ECMO cannula cultures.

Methods: the ECMO cannulas removed were analysed by cryo-scanning electron microscopy.

Results: In vivo description of Candida auris biofilm, formatted in the arterial cannula of the veno arterial ECMO.

Conclusion: The in vivo biofilm become a hidden focus of Candida auris infection.

Keywords: Extracorporeal Membrane Oxygenation; Extracorporeal Lung Support; ECMO; Candida auris; Biofilm

\section{Introduction}

The use of Extracorporeal Membrane Oxygenation(ECMO) has increased markedly. According to the Extracorporeal Life Support Organization (ELSO) report, 15.875 treatments were established worldwide in 2019. However, its use is not without complications, the most frequent being bleeding and healthcare-associated infections (HAI) [1]. Regarding HAI, rates ranging between 14 and 57 infections per 1000 days of use of extracorporeal devices are described, mainly catheter-related bacteremia and mechanical ventilationrelated pneumonia [2-5]. In neonates, most of the HAI are caused by Coagulase-negative staphylococci, while the fungi of the genus Candida (albicans, glabrata and tropicalis) predominate in the pediatric and adult populations. Recently, new emerging Candida species have been detected, with Candida auris standing out for its virulence. Since it was isolated in 2008 from a Japanese patient's ear canal [6], outbreaks have been reported worldwide. The first outbreak in Spain was described in our hospital [7]. The University Hospital La Fe in Valencia (Spain) is a third-level center, leader in the development of ventricular assistance 
and transplants (heart, lung, liver and kidney). In this article we describe the in vivo formation of biofilm by Candida auris in high-flow cannulas in a patient with a venoarterial ECMO device for cardiorespiratory support.

\section{Clinical Case}

A 44-year-old man with history of smoking was admitted to the Intensive Care Unit (ICU) with diagnosis of cardiogenic shock due to an acute myocardial infarction. Circulatory assistance with venoarterial extracorporeal membrane oxygenation was initiated. Cardiac function did not recover despite ECMO assistance and central cannulation (arterial cannula in cardiac apex) was performed 18 days later. Patient had several nosocomial infections due to multidrug resistant microorganisms and was colonized by Candida auris during an outbreak in the ICU. He received several broad-spectrum antibiotics and antifungal treatment with anidulafungin and isavuconazole, without resolution of fever. Central and peripheral cannulas of ECMO were changed and Candida auris was isolated in microbiological cultures, including blood cultures and ECMO cannulas cultures.

ECMO cannulas were also analysed by cryo-scanning electron microscopy (cryo-SEM) with a JEOL JSM-5410 microscope (Jeol, Tokyo, Japan). Catheters were cut with the aid of a scissor in small semicircular fragments. Then, they were placed in the sample holder in a concave and convex manner, to allow observation of the external and internal catheter face, respectively. After that, samples were frozen by immersion in slush nitrogen $\left(-210^{\circ} \mathrm{C}\right)$ and loaded in a Cryotrans System CT 1500 C (Oxford Instruments, United King town) to transfer them to cryo-SEM. Sublimation of surface frost at $-90^{\circ} \mathrm{C}$ for $25 \mathrm{~min}$ was performed and then samples were gold coated under vacuum conditions $(0,2 \mathrm{kPa}, 40 \mathrm{~mA})$ for $90 \mathrm{seg}$. The observation conditions were $15 \mathrm{kV}$ at $15 \mathrm{~mm}$ wd (working distance). Abundant yeasts were found on their surfaces (Figure 1). These findings show that Candida auris can develop in vivo biofilm on biomedical surfaces with a laminar and high blood flow and become a hidden focus of infection. Treatment with isavuconazole was maintained for 30 days, blood cultures were repeatedly negative and patient remained apyretic. He finally received a heart transplant and was discharged from the ICU. Unfortunately, he developed several complications during the next month, including acute graft rejection and breakthrough candidemia, and finally died.

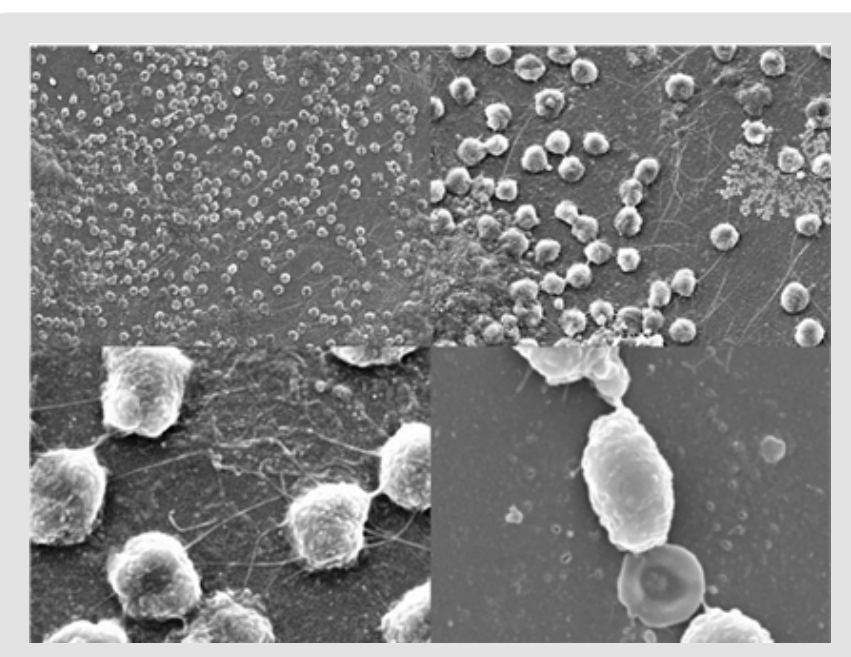

Figure 1: Candida auris in vivo biofilm on central-ECMO cannulas surfaces.

\section{Discussion}

Rates of HAI increase during ECMO treatment, specially bloodstream infections. Up to $15 \%$ of the bloodstream infections during ECMO treatment are caused by Candida species [8,9]. One of the resistance mechanisms of microorganisms is the formation of biofilms. It has been described in devices such as orotracheal tubes for mechanical ventilation, external cerebral ventricular bypass catheters and central venous catheters [10-13]. ECMO catheters can be contaminated in patients suffering a bloodstream infection [8]. Microorganisms can adhere to the catheters surface, proliferate, and form biofilms that subsequently release bacteria into the circulation and cause rapid septic deterioration [14]. In a recent study, Yeo $\mathrm{H}$ confirmed the presence of biofilms on the surfaces of ECMO cannulas from patients with acute cardiorespiratory failure. Carbapenemresistant Acinetobacter baumannii, methicillin-resistant Staphylococcus aureus, Candida parapsilopsis and tropicalis were involved [15].

The in vitro biofilm formation capacity by $C$ auris and its resistance to antifungals has sufficiently been demonstrated $[16,17]$. In our study, we have shown that Candida auris is also capable of developing in vivo biofilm in high-flow cannulas, in this case, in a central veno-arterial ECMO approach. In our opinion, a candidemia due to Candida auris during ECMO treatment would require replacement of the extracorporeal device (including cannulas). In addition, adequate anti fungal therapy should be established, given the virulence of the fungus and its ability to generate antifungal resistance through the development of biofilms. 


\section{References}

1. (2020) ECLS Registry Report. Extracorporeal Life Support Organization.

2. Bizarro MJ, Conrad SA, Faufman DA, Rycus P (2011) Extracorporeal Life Support Organization Task Force on Infections, Extracorporeal Membrane Oxygenation. Infections acquired during extracorporeal membrane oxygenation in neonates, children and adults. Pediatr Crit Care Med 12: 277-281.

3. Aubron C, Cheng A, Pilcher D, Tim L, G Magrin, et al. (2013) Infections Acquired by Adults Who Receive Extracorporeal Membrane Oxygenation: Risk Factors and Outcome. Infect Control Hosp Epidemiol 34(1): 24-30.

4. Pieri M, Agracheva N, Fumagalli L, T Greco, MD Bonis, et al. (2013) Infections occurring in adult patients receiving mechanical circulatory support: The two-year experience of an Italian National Referral Tertiary Care Center. Med Intensiva 37(7): 468-475.

5. Haneke F, Schildhauer T, Schlebes A, Strauch J, Swol J (2016) Infections and Extracorporeal Membrane Oxygenation: Incidence, Therapy, and Outcome. ASAIO J 62(1): 80-86.

6. Satoh K, Makimura K, Hasumi Y, Nishiyama Y, Uchida K, et al. (2009) Candida auris sp. nov., a novel ascomycetous yeast isolated from the external ear canal of an inpatient in a Japanese hospital. Microbiol Immunol 53(1): 41-44.

7. Ruiz Gaitán AC, Moret A, López-Hontangas JL, Jose Miguel M, Ana Isabel A, et al. (2017) Nosocomial fungemia by Candida auris: first four reported cases in continental Europe. Rev Iberoam Micol 34(1): 23-27.

8. Kim DW, Yeo HJ, Yoon SH (2016) Impact of bloodstream infections on catheter colonization during extracorporeal membrane oxygenation. J Artif Organs 19: 128-133.

9. Schilcher G, Eisner G, Hackl G, Zollner I, Krause R (2019) Candida infection of membrane oxygenator during ECMO therapy. J Infect 78 (1): 75-86.

\section{ISSN: 2574-1241}

DOI: 10.26717/BJSTR.2020.31.005078

Gimeno Costa R. Biomed J Sci \& Tech Res

This work is licensed under Creative

Commons Attribution 4.0 License

Submission Link: https://biomedres.us/submit-manuscript.php
10. Gil-Perotín S, Ramírez P, Martí V, Jose MS, Eva G, et al. (2012) Implications of endotracheal tube biofilm in ventilator-associated pneumonia response: a state of concept. Crit Care 16: R93.

11. Ramirez P, Gordón M, Soriano A, S Gile P, V Marti, et al. (2013) Assessment of the in vivo formation of biofilm on external ventricular drainages. Eur J Clin Microbiol Infect Dis 32(11): 1437-1443.

12. Yousif A, Jamal MA, Raad I (2015) Biofilm-based central line-associated bloodstream infections. Adv Exp Med Biol 830: 157-179.

13. Zhang L, Gowardman J, Morrison M, Runnegar N, Rickard CM (2016) Microbial biofilms associated with intravascular catheter-related bloodstream infections in adult intensive care patients. Eur J Clin Microbiol Infect Dis 35(2): 201-205.

14. Müller T, Lubnow M, Philipp A, Wulf SB, D Camboni, et al. (2011) Risk of circuit infection in septic patients on extracorporeal membrane oxygenation: A preliminary study. Artif Organs 35(4): E84-E90.

15. Yeo HJ, Yoon SH, Lee SE, Cho WH, Kim D, et al. (2018) Bacterial Biofilms on Extracorporeal Membrane Oxygenation Catheters. ASAIO J 64(4): e48-e54.

16. Larkin E, Hager C, Chandra J, Mukherjee P, Retuerto M, et al. (2017) The Emerging Pathogen Candida auris: Growth Phenotype, Virulence Factors, Activity of Antifungals, and Effect of SCY-078, a Novel Glucan Synthesis Inhibitor, on Growth Morphology and Biofilm Formation. Antimicrob Agents Chemother 61(5): e02396-e02416.

17. Sherry L, Ramage G, Kean R, Borman A, Johnson E, el al. (2017) BiofilmForming Capability of Highly Virulent, Multidrug-Resistant Candida auris. Emerg Infect Dis 23(2): 328-331.

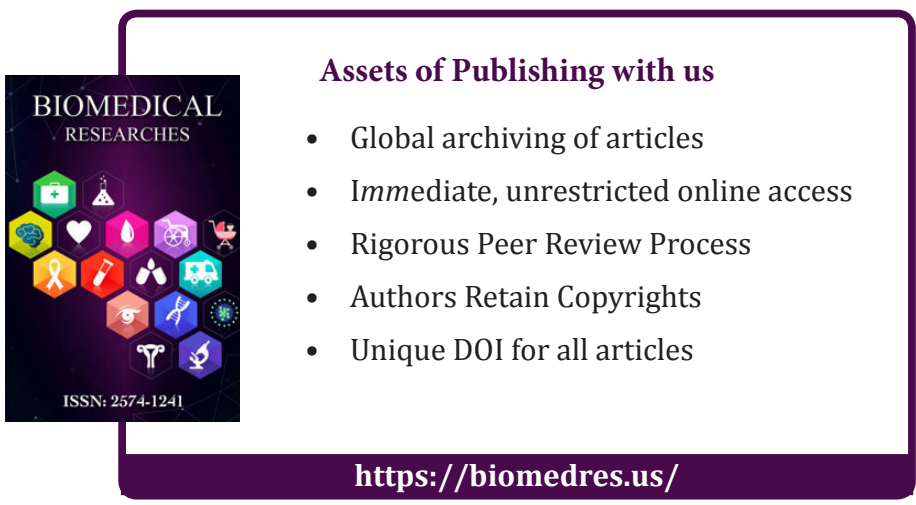

